\title{
Irrigation Management Transfer: A New Methodology to Improve the Performance of Agency Managed Irrigation Systems (AMISs)
}

\author{
Achyut Man Singh
}

Abstract: This paper presents a new concept on the management of Agency Managed Irrigation Systems with the joint participation of the agency and the users, with their defined roles and responsibilities. The message of the system governance and operation methodology are disseminated to the grass root level of the users. Resource management and water charge collection are anticipated to be firmly applied in the system. The users and Water User's Association and also Department of Irrigation field staff will be well trained in the Irrigation Management Transfer process with capacity building. For sustainability, monitoring and evaluation with independent auditing are part of the process. The general Irrigation Management Transfer procedures adopted by Department of Irrigation are redefined to this new concept in the World Bank assisted Irrigation and Water Resources Management Project.

Key words: Irrigation management transfer, water users, AMIS, World Bank, Nepal

\section{Background}

Trigation system is a dynamic self regulating 1 system comprising its elements of operation mode on Physical, Institutional, Social, and Financial systems. Successful irrigation systems, either Farmer's Managed Irrigation Systems (FMIS) or Agency Managed Irrigation Systems (AMIS) performing efficiently in their service delivery to the end users, have demonstrated a balanced operation and management of these four elements. A vast literature regarding irrigation system performance and efficient operation techniques has been developed focusing either in physical, institutional or social systems. Experiences from Irrigation Management Transfer (IMT) Projects and their evaluations have indicated that sustainable irrigation systems have a balanced management approach with the implementation on these four elements.

These are:

\section{Physical System}

The physical system of an irrigation scheme comprises of its infrastructures such as:

(i) acquisition (head works, intake, or pumping system or any other means of tapping water from the resources),

(ii) conveyance (canals and distribution system),

(iii) regulating, and

(iv) facilitating infrastructures (such as silt ejectors, settling basin and other accessories).

For equitable water delivery to all the beneficiaries of the command area, the physical system must be in an efficient operational state, without which unbalanced distribution of irrigation water delivery occurs damaging the performances of the systems.

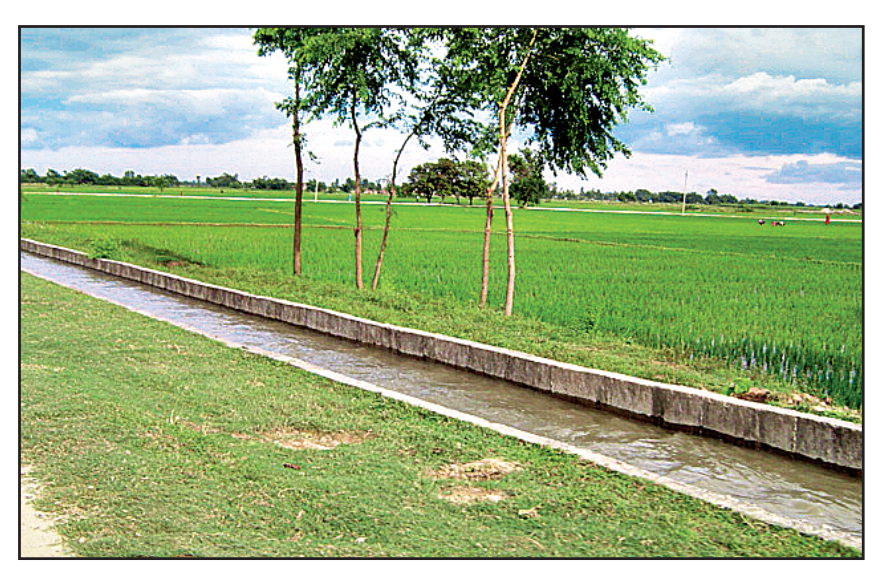

Distributary Canal

\section{Institutional Aspects}

Distribution of irrigation water delivery requires skilled hydraulic calculations and management to convey the water source from its river (or other) to the farmer's field. These works could be carried out by hydraulic or irrigation engineer and the implementation of the water delivery schedule could be delegated to the subsequent units of operators and to the water user association. In addition to the hydraulic management of water sources, maintenance of the systems require skilled manpower to make a plan. For this, the institution of the irrigation system must be competent to carry out the job efficiently. The implementation of the canal operation and maintenance is carried out jointly with the Water User's Association (WUA) and skilled manpower from the Department of Irrigation (DOI). The institution of DOI and WUA for the operation and management of the irrigation system must be efficient and dedicated for the right performance of the system.

\section{Social Aspects}

Discipline in sharing the water of the irrigation system is vital for its efficient performance. The water 
users are to be well oriented and disciplined to comply with the rules and regulations as well as the water sharing arrangement. For this, the WUA must be active, along with all the beneficiaries of the water sharing. Therefore, a socially balanced structure of the WUA representatives from the very grass roots level unit as outlet level is required. Awareness about water delivery and enforcement of the rules, regulations and water sharing arrangements must be strictly implemented. Vandalism and defaulters must be penalized in order to create a well performed irrigation system. This social aspect of the irrigation system is as important as the other elements of the system. Awareness campaigns, capacity building and good governance of the system are also essential.

\section{Financial Management}

The resources for the financial support to run an irrigation system rely on the government budget, water charges, and fines for defaulters. The mechanism of budgeting for the operation and maintenance works must be transparent to all the users in order to involve them closely for their contribution of water charges, and to ensure that they are rightly and properly utilized. A proper system has to be developed to carryout the financial aspect of the system. A new approach of preparing total financial management plan has developed in recent years for the Irrigation and Water Resources Management Project (IWRMP). This aspect is also vital in the overall performances of the system.

\section{The Concept}

The performance of an irrigation system depends entirely on the proper management of the four elements above. Any shortcomings could jeopardize system performances. The managers of the irrigation system are responsible for the proper working of the physical systems, delivering efficient services to the end users; whereas, the end users and their organizations should watch carefully after the enforcement of water delivery, the timely payment of water charges, and routine maintenance of the system. The UN Food and Agriculture Organization (FAO) has developed software to improve the physical performances of the irrigation system. It is called MASSCOT, and is used for the hydraulic analysis of the prevailing infrastructures. The concept behind this program is to calibrate the system with the appropriate water delivery system by diagnosing its hydraulic performances. The type of gates, distribution structures and conveyance structures determines the performance indicators.

On the social side, it is envisaged that the end users at the very grass roots level (i.e., outlet unit) should be oriented and be convinced about the functioning of the system. Water distribution among the farmers and sincerity in the maintenance of their sub-systems with timely payment of the water charges are their key activities that govern the efficient functioning of the irrigation system. Individual end users, and the water users association as a whole, must be active and aware towards the functioning of their sub-system organization. The engineering division and the WUA's are to be co-partners in the implementation and execution of the operation and maintenance of the irrigation system. Key indicators for their roles include Governance, Financial arrangements and Capacity building as discussed below.

\section{Governance}

Governance of the irrigation system is arranged through four aspects:

1) Respective defined roles and responsibilities of the WUA and the agency (DOI in the case of Nepal); these will be defined through an 'Irrigation Management Transfer Arrangement'.

2) A Scheme Co-ordination Committee will be set up at the system level in which the local bodies, WUA members, agencies (DOI), nongovernment organizations (NGOs) and representatives from local governments will participate. This committee will co-ordinate and monitor the plans and actions performed by the agencies and WUAs. The rate of water charges to be collected from the user's to meet the regular operation and maintenance requirements of the system will be established.

3) Enhancing transparency and accountability through the tools of benchmarking, rapid appraisal of the systems with end user's satisfaction, and water measuring devices to monitor the water delivery relative to the entitlement of different users.

4) Periodic rapid evaluation of the scheme performance and user satisfaction, and installation of water measuring devices as a means to monitoring water delivery relative to the entitlements of different water users group.

\section{Financing Arrangements}

A detailed inventory of the assets of the irrigation system is carried out and an Asset Management Plan is prepared. These plans will define the operation and maintenance (O\&M) needs of the entire system to be agreed upon between the WUA and the agency (DOI). These will form a basis for a commitment by the agency to fund O\&M and other essential structure improvement works, which the WUA will be committed to collect the requirements through their labor and cash contribution. The respective contributions will be monitored by the Scheme Co-ordination Committee. 


\section{Capacity Building}

The WUA's need to be competent enough to participate in the O\&M of the system and take respectively of the functioning of the system or subsystem. For this to happen, capacity building activities must be developed to bring them to a satisfactory level. This actively includes training and orientation to the WUA's on:

(a) technical skills with regard to joint preparation of Asset Management Plans,

(b) undertaking and supervising the O\&M activities,

(c) provision of efficient and equitable irrigation service delivery, and

(d) collection of relevant charges including action against defaulters.

In the mean time the staff of the agency (DOI) has also to be trained and oriented to establish an efficient governance system. Their fields are as below: (a) the agency's new role is to prepare Asset Management Plan and transfer them to WUA's,

(b) develop efficient arrangements for rehabilitation and maintenance (including contracting and outsourcing as appropriate), and

(c) benchmarking, rapid appraisal, and monitoring the system performances (canal operation technology using the MASSCOT software could be applied to enhance the performance).

\section{Proposed Implementation Arrangement}

As mentioned earlier, the two prime stakeholders, the DOI and the WUAs, are to work side by side as partners in the implementation of the IMT process as well as in O\&M activities of the irrigation systems. Organization set up as envisaged in the IWRMP for implementations are illustrated in Figure 1.

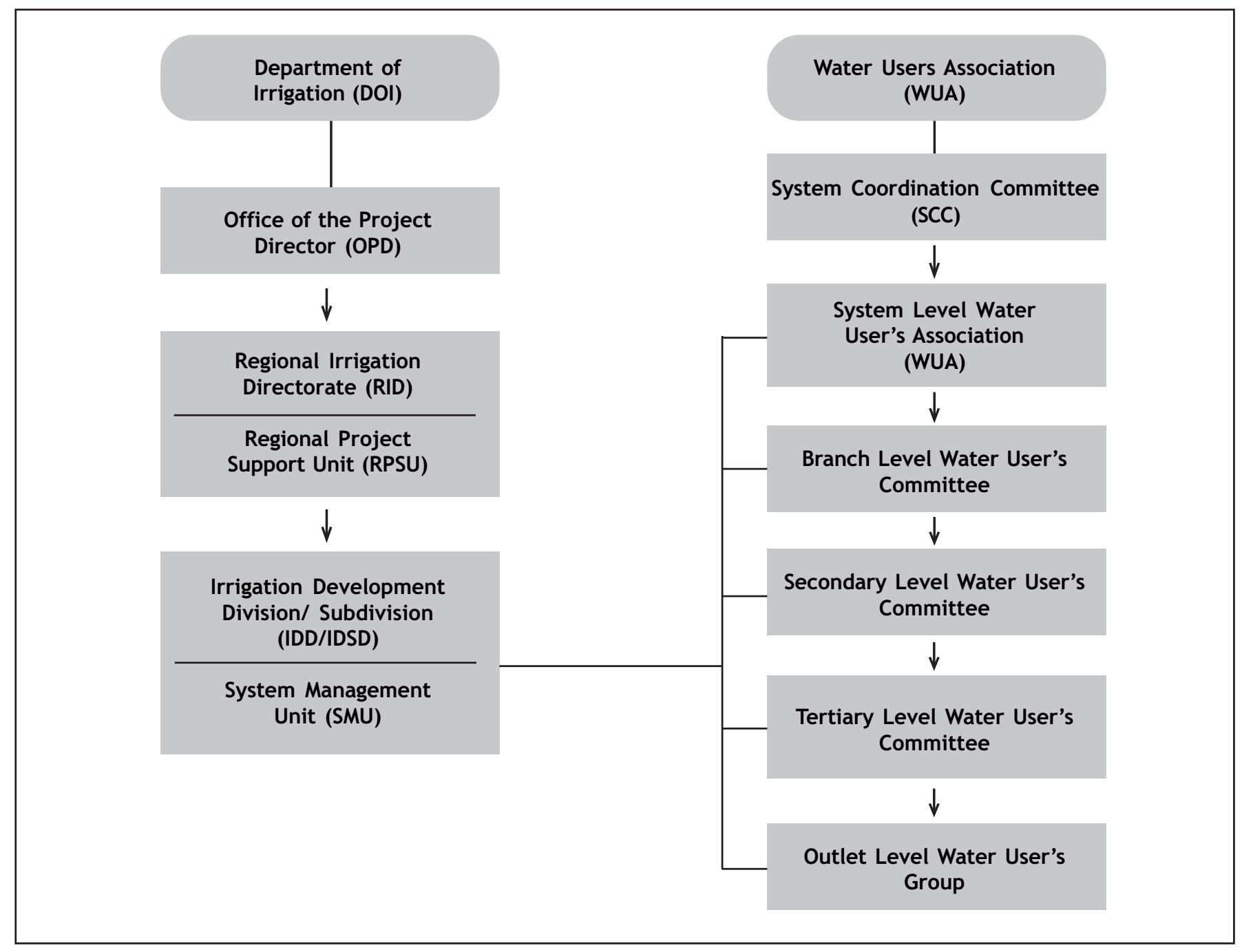

Figure 1. Organization Set Up for Irrigation Management Transfer 
It is envisaged that the ground level unit of System Management Unit (SMU) and the WUAs will be working closely together to implement the activities designed for the Irrigation Management Transfer of the irrigation systems. The water users in the system should be organized to form the groups and committees at all levels of the canal hierarchy. Each of the committees is to be involved invariably in the system management as well as the water distribution activities. A primary theme of the new concept is that the water users are to be sensitized, oriented and trained as required to perform their part of the works. There will be well defined demarcation of roles and responsibilities of the two actors, DOI and WUA, which will be illustrated in the Asset and Financial Management Plan, and the agreement between the WUAs and the DOI. One dramatic differences between the previous IMT processes and procedures and this new concept is that the WUAs will take over the responsibility of the system with the transfer agreement first, then only the other detailed activities of ESI and system diagnosis and other capacity building activities will be launched. Unless the WUAs and the beneficiaries are ready for take over, further works are not carried out. The consultation process will be the pivotal activity to acquaint and orient the farmers and the WUA.

Based on the experiences of the Irrigation Management Transfer Project in the past and many other IMT activities carried out in other countries such as Mexico and Indonesia, the procedural guidelines for the management transfer has been prepared for IWRMP. The whole procedure is categorized into four stages with the incorporation of various activities, as discussed below.

\section{Stage I: System Identification for IMT}

A basic principal in the system selection for IMT is to find the existing systems or sub-systems of AMIS that are operational at present, where no major rehabilitation works are required for smooth water delivery up to the lowest level or even at the tail end positions. The second primary criteria are to find the attitudinal aspects of WUA or the users to take over the system or sub-system as their responsibility. Other various activities in this stage could be identified as below:

- selection of IMT candidates,

- approval by IWRMP Steering Committee, and

- consultation process and basic information collection.

Under Basic Information Collection, the agency will have to collect and initiate preparation of the following documents:

- rapid appraisal of the system (RAP),

- asset inventory preparation,

- benchmarking of the system,
- WUA membership list, and

- parcellary map preparation.

Furthermore, there will be two consultation activities with the beneficiaries at various levels, including taking feedback from them and evaluating their willingness to take over the management responsibilities. The draft Irrigation Management Transfer Agreement document between the DOI and WUA will be disseminated to the user's committee and sub-committees to the lowest level. After intense consultation regarding the roles and responsibility of WUA's and DOI the further activities are initiated for IMT process.

\section{Stage II: Preparation for IMT Implementation}

In this stage the proposed agreement documents and by-laws of the WUAs will be finalized, taking the third round of consultation. In the meantime, the supporting documents of the systems such as RAP, benchmarking, Asset and Financial Management Plan, Essential Structure Improvement (ESI) Plan, and Agriculture Development Plan will also be prepared and finalized.

The following issues will be discussed and finalized during this stage:

- agreement between DOI and WUA,

- acceptance to take responsibility of O\&M of the systems/sub-systems to be handed over,

- acceptance of the collection of ISF for the O\&M of the targeted systems, and

- amendment and approval of the WUA's constitution.

In the meantime both the WUA and DOI will carry out the following activities:

- WUA formation at all levels,

- consultation at all levels,

- cost sharing basis for the essential structure improvement works, and

- finalization of the supporting documents RAP, benchmarking, Asset and Financial Management Plan, Essential Structure Improvement Plan, and Agriculture Development Plan. These are to be prepared in a participatory basis with the users.

The consultation processes are to be carried out in close coordination with WUA members at all levels. Activities regarding the engineering, social and management aspects will be duly prepared by experts and will be consulted and finalized with the WUA for final implementation of the IMT of the systems. In this case both the DOI and WUA will have equal roles in their finalization, with assistance from the local consultants or NGOs. In this case, the Water 
Management Plan of the whole system will be diagnosed and prepared by the engineers taking assistance from expert hydraulic engineer to assess the functionality of the system infrastructures. In IWRMP it is envisaged that MASSCOT approach developed by FAO will be applied to evaluate system performance and draw up the Water Management Plan accordingly. The DOI engineers will be trained to use the software and it will be applied in other systems.

\section{Stage III: Institutional Strengthening for IMT}

Under institutional strengthening for IMT both WUAs and DOI personnel involved in the project are to be oriented and trained to make it a success. The following activities will be undertaken under this stage.

- WUA and field staff capacity development,

- WUA institutional development,

- prioritization of ESI through WUA participation,

- irrigation system improvement works, and

- flow measurement at different level and preparing Water Management Plan.

These activities pertain to the IMT process implementation, in order to bring the capacity of WUA and DOI personnel to perform proper execution of the project and in sustainable O\&M of the system. The capacity building of personnel will have to involve the following aspects:

- review of the objectives of IMT program,

- reassessment of consultation process and promotion of farmer's participation in the IMT, about the IMT agreement and Bye laws of WUA,

- water distribution methods,

- awareness regarding the responsibility of farmers and WUA's after taking over the scheme,

- account keeping for the various kinds of contributions, including labor, material and cash resources of WUAs, and

- operation and maintenance regarding their system and sub-system.

Regarding WUA institutional development, the training subjects will focus on:

- organizational capacity improvement,

- leadership at different level,

- rules and regulations of WUAs,

- WUA record system,

- effective planning, implementation and monitoring,

- operational plan implementation,

- financial management plan implementation,
- maintenance plan implementation,

- implementation of water delivery schedules, and

- agricultural plan implementation.

Prioritization of the ESI will be made through joint work through by DOI and WUA personnel and by assessing the urgency of the required improvement works. A construction committee will be formed from WUA members and the System Management Unit (SMU) to supervise the construction works on ESI. The ESI works could be subdivided into three categories as: (1) the WUA part of works to be contributed by them, (2) part of the DOI share of works, which are simple and easier and can be contracted to the WUA, and (3) those works which are complex in nature and need skilled hands and resources to construct should be contracted to the professional contractors or builders.

It is envisaged that the project staff with assistance from the TA team or hydraulic experts will carry out the hydraulic analysis of the system and develop a water management plan, optimizing the water distribution with the available water resources. The operational plan will be developed for three seasons (summer, winter and spring) as variations occur in the available water source as well as in cropping patterns. The plan will be oriented and disseminated to the DOI field staff and WUA members/gate operators for efficient and equitable water distribution. Guidelines for canal operation, maintenance, and management will be prepared by the TA team for the use of these field staff and WUA members.

\section{Stage IV: Monitoring, Evaluation and Agriculture Activities}

It is important that implementation of the IMT be monitored and evaluated from time to time to track its successful execution and firm outputs. The monitoring and evaluation (M\&E) of the functionality of the system and sub-system, and necessary improvement works, are to be carried out periodically for keeping performance on track. The system office and the WUA will be regularly monitoring and evaluating performance, so that they can check on fast deterioration of the system due to negligence. An external agency is also to be employed for the evaluation of the project implementation. The National Vigilance Center can also be used for technical auditing purposes. In the meantime, the System Coordination Committee (SCC) also will evaluate scheme performance independently. Assistances to the WUA for operation and maintenance will be required to carry out the works as envisaged and will be guided by the expert's recommendations. Monitoring and evaluation activities will focus on the physical, management and social aspects as follows:

- physical system or sub-system
performances, 
- WUA institutional or management performances, and

- social, operation and maintenance performances.

Under physical system, the M\&E activities will focus on performance of the different components of the irrigation systems; i.e., the headworks, main canal, branch or secondary canals, and tertiary system. Various tools of monitoring such as RAP, benchmarking and flow measurement techniques will be applied. In institutional or management aspects the WUA's functioning, their record keeping, regular meetings and others will be monitored. Under social aspects the collection of water charges, penalty to defaulters, equitable distribution of water, and agricultural activities will be monitored for overall impact on the irrigation management transfer.

\section{Expected Outputs From IMT Process}

It is expected that the IMT process will have positive impact on the overall performances of the system in physical, management and social aspects for the betterment of the farmers' livelihoods. The envisaged outputs could be assessed as follows:
a) responsive management improvement of DOI,
b) increased responsibility of O\&M taken by WUAs,
c) provision of demarcation of responsibility between DOI and WUA adhered,
d) increased contribution of resources by beneficiaries for $\mathrm{O} \& \mathrm{M}$,
e) increased agriculture production, and
f) increased income of farmers of the system.

A flow chart of the procedural steps is shown in Figure 2.

\begin{tabular}{l} 
Stage 1: System Identification for IMT \\
\begin{tabular}{|l|}
\hline Selection of IMT Candidates \\
Approval by Steering Committee Decisions
\end{tabular} \\
\hline 1. Consultation Process and Basic Information Collection \\
\hline 1st Consultation Information Sharing 1.1 Basic Information \\
Collection 2nd Consultation
\end{tabular}

Stage 2: Preparation for IMT Implementation Interaction between WUA and DOI 3rd Consultation

Agreement between DOI and WUA

Stage 3: Institutional Strengthening for IMT Institutional Development and Irrigation System ImprovementImplementation of O\&M by DOI and WUA

Stage 4: Monitoring, Evaluation and Agriculture Activities

Regular Monitoring, Evaluation and Agriculture Support

Figure 2. IMT Implementation Procedure Steps

Achyut Man Singh is Senior Irrigation Engineer in MULTI Disciplinary Consultant Pvt. Ltd., Kathmandu, Nepal.

Corresponding address: singham@wlink.com.np

\section{References}

World Bank, 2007, Project Appraisal Document: 'Irrigation and Water Resources Project' (Nepal), Kathmandu: The World Bank.

Renault, Daniel, Thierry Facon and Robina Wahaj, 2007, Modernizing Irrigation Management the MASSCOT Approach, FAO Irrigation and Drainage Paper No 63, Rome, Food and Agriculture Organization of the United Nations. 